ARTICLE

\title{
Origin of stabilization and destabilization in solid-state redox reaction of oxide ions for lithium-ion batteries
}

\author{
Naoaki Yabuuchi ${ }^{1}$, Masanobu Nakayama ${ }^{2,3}$, Mitsue Takeuchi ${ }^{4}$, Shinichi Komaba ${ }^{4}$, Yu Hashimoto ${ }^{2}$, \\ Takahiro Mukai ${ }^{2}$, Hiromasa Shiiba ${ }^{2}$, Kei Sato ${ }^{1}$, Yuki Kobayashi ${ }^{1}$, Aiko Nakao ${ }^{5}$, Masao Yonemura ${ }^{6,7}$, \\ Keisuke Yamanaka ${ }^{8}$, Kei Mitsuhara ${ }^{8} \&$ Toshiaki Ohta $^{8}$
}

Further increase in energy density of lithium batteries is needed for zero emission vehicles. However, energy density is restricted by unavoidable theoretical limits for positive electrodes used in commercial applications. One possibility towards energy densities exceeding these limits is to utilize anion (oxide ion) redox, instead of classical transition metal redox. Nevertheless, origin of activation of the oxide ion and its stabilization mechanism are not fully understood. Here we demonstrate that the suppression of formation of superoxide-like species on lithium extraction results in reversible redox for oxide ions, which is stabilized by the presence of relatively less covalent character of $\mathrm{Mn}^{4+}$ with oxide ions without the sacrifice of electronic conductivity. On the basis of these findings, we report an electrode material, whose metallic constituents consist only of $3 d$ transition metal elements. The material delivers a reversible capacity of $300 \mathrm{mAhg}^{-1}$ based on solid-state redox reaction of oxide ions.

\footnotetext{
${ }^{1}$ Department of Green and Sustainable Chemistry, Tokyo Denki University, 5Senju Asahi-Cho, Adachi, Tokyo 120-8551, Japan. ${ }^{2}$ Frontier Research Institute for Materials Science, Nagoya Institute of Technology, Gokiso-cho, Showa-ku, Nagoya, Aichi 466-8555, Japan. ${ }^{3}$ Japan Science and Technology Agency (JST), PRESTO, 4-1-8 Honcho Kawaguchi, Saitama 332-0012, Japan. ${ }^{4}$ Department of Applied Chemistry, Tokyo University of Science, 1-3 Kagurazaka, Shinjuku, Tokyo 162-8601, Japan. ${ }^{5}$ Bio-engineering Lab., Riken, 2-1 Hirosawa, Wako, Satimata 351-0198, Japan. ${ }^{6}$ Institute of Materials Structure Science (IMSS), High Energy Accelerator Research Organization (KEK), 1-1 Oho, Tsukuba, Ibaraki 305-0801, Japan. ${ }^{7}$ Department of Materials Structure Science, Sokendai (The Graduate University for Advanced Studies), 203-1 Shirakata, Tokai, Ibaraki 319-1106, Japan. ${ }^{8}$ SR Center, Ritsumeikan University, 1-1-1 Noji-Higashi, Kusatsu, Shiga 525-8577, Japan. Correspondence and requests for materials should be addressed to N.Y. (email: yabuuchi@mail.dendai.ac.jp).
} 
$\mathrm{R}$ echargeable lithium-ion batteries (LIBs) are widely used in our daily life because LIBs have the highest gravimetric/ volumetric energy density among commercial energy storage devices. LIBs are used as a power source for zero emission electric vehicles and are expected to be used for grid energy storage ${ }^{1}$. LIBs are becoming a key technology enabling a shift from fossil fuel to renewable electric energy, which potentially realizes green and sustainable energy development in the future. Nevertheless, the possibility of further increase in the energy density is severely restricted because of unavoidable theoretical limits for positive electrodes, such as spinel-type oxides and iron phosphates.

In contrast to these materials, which are currently used in the commercial LIB, there is room for further increase in the energy density for layered oxides, such as $\mathrm{LiCoO}_{2}$ (ref. 2), $\mathrm{LiNi}_{1 / 2} \mathrm{Mn}_{1 /}$ ${ }_{2} \mathrm{O}_{2}$ (ref. 3), $\mathrm{Li}_{2} \mathrm{MnO}_{3}$ (ref. 4) and those derivatives ${ }^{5-7}$. Among them, $\mathrm{Li}_{2} \mathrm{MnO}_{3}$-based electrode materials have been extensively studied as positive electrode materials in the past decade $e^{6,8-15}$. The reaction mechanism of this material was a controversial subject for a long time. Since the oxidation state of manganese ions is tetravalent, oxidation of manganese ions beyond the tetravalent state is difficult. Instead of manganese ions, negatively charged anions, oxide ions $\left(\mathrm{O}^{2-}\right)$, donate electrons on charge (electrochemical oxidation). However, oxidation of oxide ions results in partial loss of oxygen as an irreversible process, that is, decomposition reaction ${ }^{8}$. The loss of oxygen induces the formation of trivalent manganese ions on discharge (electrochemical reduction), leading to the unfavourable phase transition in the layered structure ${ }^{11}$. Nevertheless, it has been evidenced that reversible solid-state redox for oxide ions is possible for the $\mathrm{Li}_{2} \mathrm{RuO}_{3}$-based system, which essentially has the same crystal structure as $\mathrm{Li}_{2} \mathrm{MnO}_{3}$, and the contribution of oxide ions has been experimentally evidenced by using an arsenal of characterization techniques ${ }^{14}$ and theoretical method ${ }^{16}$. Very recently, the formation of peroxo-like dimers in $\mathrm{Li}_{2-x} \mathrm{IrO}_{3}$ has been experimentally visualized by transmission electron microscopy $^{17}$ whereas recent experimental ${ }^{18}$ and theoretical ${ }^{19}$ studies have suggested that an isolated hole is formed on the charge process for lithium-excess electrode materials. Enrichment of lithium ions as the highly ionized cation results in a less covalent character for oxide ions, and thus the oxide ions are more easily oxidized compared with conventional oxides with late transition metals. Therefore, it has been proposed that the holes in the oxygen $2 p$ orbital is effectively stabilized ${ }^{18,19}$.

The use of anion redox, especially oxide ions, is a crucial strategy to design and develop new electrode materials with high gravimetric/volumetric energy density for LIB. Reversible capacity of electrode materials is potentially further increased by the enrichment of lithium contents with less transition metals in the close-packed structure of oxide ions. Recently, our group has reported that $\mathrm{Li}_{3} \mathrm{NbO}_{4}$ (refs 20,21) and $\mathrm{Li}_{4} \mathrm{MoO}_{5}$ (ref. 22), which have higher lithium contents than those of $\mathrm{Li}_{2} \mathrm{MnO}_{3}$ and $\mathrm{Li}_{2} \mathrm{RuO}_{3}$, are potentially utilized as host structures for a new series of high-capacity electrode materials. Similar concepts are also proposed in the literature ${ }^{23,24}$. Manganese-substituted $\mathrm{Li}_{3} \mathrm{NbO}_{4}$, $\mathrm{Li}_{1.3} \mathrm{Nb}_{0.3} \mathrm{Mn}_{0.4} \mathrm{O}_{2} \quad\left(0.43 \mathrm{Li}_{3} \mathrm{NbO}_{4}-0.57 \mathrm{LiMnO}_{2}\right)$, delivers large reversible capacity (approximately $300 \mathrm{mAhg}^{-1}$ ) with reversible solid-state redox reaction of oxide ions ${ }^{20}$. Similar to pentavalent niobium, a material with pentavalent antimony, $\mathrm{Li}_{4} \mathrm{FeSbO}_{6}$, has been recently reported ${ }^{25}$. Solid-state redox reaction of oxide ions is also activated in $\mathrm{Li}_{4} \mathrm{FeSbO}_{6}$, and a reductive coupling mechanism as an irreversible process has been evidenced in this system. As a non-rocksalt system, the use of Codoped $\mathrm{Li}_{2} \mathrm{O}$ has been also proposed ${ }^{26}$. Although many articles now describes the anion redox for battery materials, the border between reversibility and irreversibility for the solid-state redox reaction of oxide ions remains unclear, and it is a critical point to understand the factors affecting reversibility of anion redox.

In this article, we answer these questions through systematic studies on $\mathrm{Li}_{3} \mathrm{NbO}_{4}-\mathrm{LiMeO}_{2}(\mathrm{Me}=\mathrm{Fe}, \mathrm{Mn}$ and $\mathrm{V})$ binary system. Reversibility of the solid-state redox reaction highly depends on the transition metal elements selected, which correlates with the formation of electrochemically unstable superoxide species because of charge transfer from oxidized oxide ions. Furthermore, on the basis of these findings, we demonstrate a niobium-free high-capacity positive electrode material, which effectively utilizes reversible solid-state redox reaction of oxide ions. These findings can potentially enable highenergy LIBs free of less abundant transition elements, such as cobalt and nickel ions.

\section{Results}

Synthesis and characterization of $\mathrm{Li}_{3} \mathrm{NbO}_{4}-\mathrm{LiMeO}_{2}$ system. Figure 1 summarizes characterization of $\mathrm{Li}_{3} \mathrm{NbO}_{4}-\mathrm{LiMeO}_{2}$ $(\mathrm{Me}=\mathrm{Fe}, \mathrm{Mn}$ and $\mathrm{V})$ binary system by synchrotron X-ray diffraction (SXRD) and SEM. $\mathrm{Li}_{3} \mathrm{NbO}_{4}$ crystallizes into a cationordered rocksalt-type structure while a lack of $d$ electrons in a conduction band results in an insulating character. Substitution of $3 d$ transition metal ions for $\mathrm{Nb} / \mathrm{Li}$ ions effectively induces conductive electrons, and colour of samples is also changed from white for $\mathrm{Li}_{3} \mathrm{NbO}_{4}$ to black for substituted samples with $\mathrm{Mn}^{3+}$ and $\mathrm{V}^{3+}$. Such $3 d$ transition metals can accept electrons from oxide ions. However, a change in the crystal structure is also unavoidable, and formation of a cation-disordered rocksalt-type structure is found. Recently, electrode materials with the cationdisordered rocksalt-type structure, such as $\mathrm{Li}_{1.211} \mathrm{Mo}_{0.467} \mathrm{Cr}_{0.3} \mathrm{O}_{2}$ (ref. 27) and $\mathrm{Li}_{1.33} \mathrm{~V}_{0.67} \mathrm{O}_{1.33} \mathrm{~F}_{0.67}$ (ref. 28), have been reported as

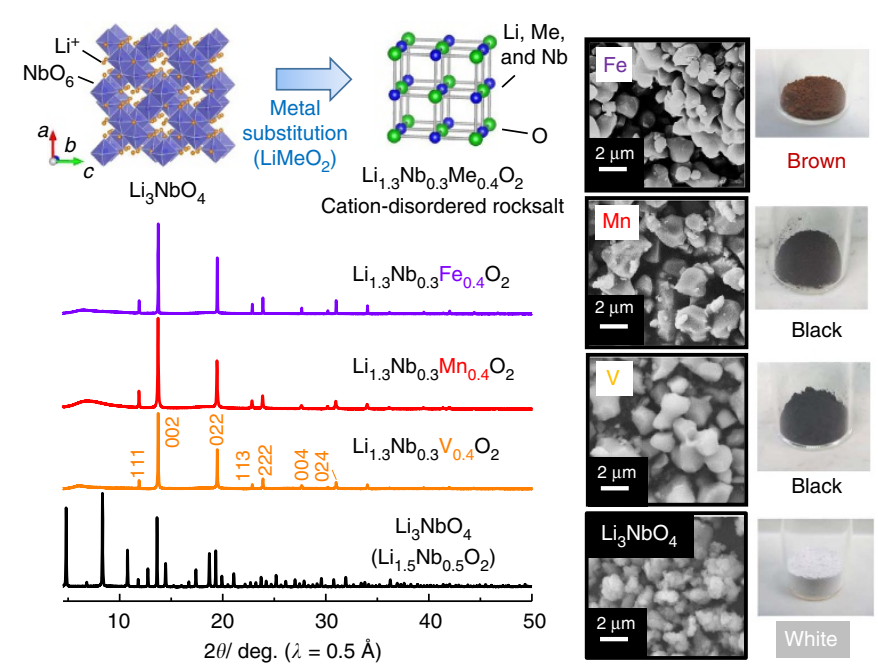

Figure 1 | Crystal structures and particle morphology of $\mathbf{L i}_{\mathbf{1 . 3}} \mathbf{N b}_{\mathbf{0 . 3}} \mathbf{M e}_{\mathbf{0 . 4}} \mathbf{O}_{\mathbf{2}}$. Synchrotron X-ray diffraction (SXRD) patterns of as-prepared $0.43 \mathrm{Li}_{3} \mathrm{NbO}_{4}-0.57 \mathrm{LiMeO}_{2}\left(\mathrm{Me}=\mathrm{Fe}^{3+}, \mathrm{Mn}^{3+}\right.$, and $\left.\mathrm{V}^{3+}\right)$ samples, which are reformulated as $\mathrm{Li}_{1.3} \mathrm{Nb}_{0.3} \mathrm{Me}_{0.4} \mathrm{O}_{2}$ based on the formulation of $\alpha-\mathrm{NaFeO}_{2}$-type layered structure, are shown. SXRD patterns of the samples, $\mathrm{Me}=\mathrm{Fe}^{3+}$ and $\mathrm{Mn}^{3+}$, were also shown in our previous work ${ }^{20}$. The samples crystallize into the cation disordered rocksalt structure with lattice parameters of $4.19 \AA$ for $\mathrm{Fe}^{3+}, 4.21 \AA$ for $\mathrm{Mn}^{3+}$ and $4.17 \AA$ for $\mathrm{V}^{3+}$. Structural analysis was carried out using RIETAN-FP (ref. 41). Substitution of $\mathrm{Fe}^{3+}, \mathrm{Mn}^{3+}$ and $\mathrm{V}^{3+}$ for $\mathrm{Nb}^{5+} / \mathrm{Li}^{+}$results in the donation of $d$ electrons in a conduction band, and thus colour of the samples changes from white for $\mathrm{Li}_{3} \mathrm{NbO}_{4}$. Data of $\mathrm{Li}_{3} \mathrm{NbO}_{4}\left(\mathrm{Li}_{1.5} \mathrm{Nb}_{0.5} \mathrm{O}_{2}\right)$ are also shown for comparison. Schematic illustrations of the crystal structures were drawn using the program VESTA (ref. 42). 
high-capacity electrode materials. Historically, such cationdisordered rocksalt phase had been regarded as electrochemically inactive as electrode materials because of a lack of the Li migration path in a bulk structure. Nevertheless, formation of percolating network for the Li-excess system $\left(\mathrm{Li}_{1+x} \mathrm{Me}_{1-x} \mathrm{O}_{2}\right)$ opens the path for Li migration in the cationdisordered rocksalt-type structure ${ }^{27}$.

Electrochemistry of $\mathrm{Li}_{3} \mathrm{NbO}_{4}-\mathrm{LiMeO}_{2}$ system in half-cells. Although as-prepared samples with primary particle size of $2-3 \mu \mathrm{m}$ show insufficient electrode performance ${ }^{20}$, mechanical ball milling with carbon (reduction of particle size with uniform mixing with carbon is achieved in Supplementary Fig. 1) effectively improves the electrode performance of the samples in Li cells. Electrode performance is further improved at elevated temperature $\left(50^{\circ} \mathrm{C}\right)$, and three cation-disordered rocksalt samples, $\mathrm{Li}_{1.3} \mathrm{Nb}_{0.3} \mathrm{Me}_{0.4} \mathrm{O}_{2} \quad\left(\mathrm{Me}=\mathrm{Fe}^{3+}, \mathrm{Mn}^{3+}\right.$ and $\left.\mathrm{V}^{3+}\right)$, deliver large reversible capacities in Li cells, as shown in Fig. 2. It is noted that three $\mathrm{Li}_{3} \mathrm{NbO}_{4}$-based samples with different $3 d$ transition metals show quite different electrochemical behaviour. The Fe system shows a large initial charge (oxidation) capacity of $350 \mathrm{mAh} \mathrm{g}^{-1}$ that is quite close to that of the theoretical capacity $\left(383 \mathrm{mAhg}^{-1}\right)$ as defined by the extraction of all $\mathrm{Li}^{+}$ions (1.3 moles) from the crystal lattice. However, a clear change in a voltage profile is found on the second charge process, which is totally different from the first charge process. A well-defined voltage plateau is observed on the initial charge, but an S-shaped profile is noted after first discharge process. Polarization is small for the S-shaped profile centred at $2.5 \mathrm{~V}$, which will be discussed in the later section. The voltage plateau is not observed for the $\mathrm{V}$ system, and the sample shows S-shaped profile from the initial charge process. The observed reversible capacity is comparable to that of a theoretical capacity based on $\mathrm{V}^{3+} / \mathrm{V}^{5}+$ two-electron redox $\left(236 \mathrm{mAh}^{-1}\right)$ and is much smaller than that expected from lithium contents in the structure. The Mn system delivers a large discharge capacity of $300 \mathrm{mAh} \mathrm{g}^{-1}$ with the appearance of voltage plateau as reported in our literature ${ }^{20}$. Capacity retention of the samples is compared in Supplementary Fig. 2 at room temperature. Although the Mn system shows large reversible capacity, the $\mathrm{V}$ and Fe systems show better capacity retention in $\mathrm{Li}$ cells. Quasi-open-circuit voltage (QOCV) of the samples at 25 and $50^{\circ} \mathrm{C}$ are also compared in Fig. 2b. The Fe system shows quite small polarization with flat QOCV at $4 \mathrm{~V}$ on charge whereas huge polarization $(>1.5 \mathrm{~V})$ is observed on discharge at $25^{\circ} \mathrm{C}$. The polarization is significantly reduced at $50{ }^{\circ} \mathrm{C}$. The $\mathrm{V}$ system shows the smallest polarization on charge/discharge with an S-shaped voltage profile as expected from galvanostatic curves (Fig. 2a). Two different regions are observed for the Mn system on charge; relatively small polarization for the sloping region a

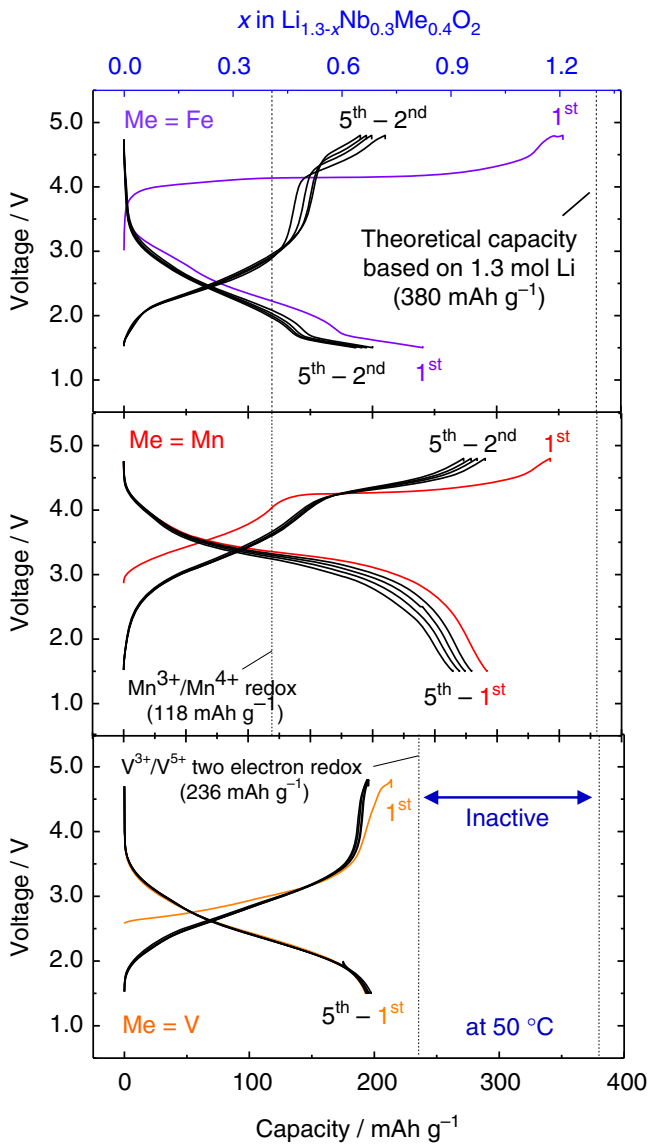

b
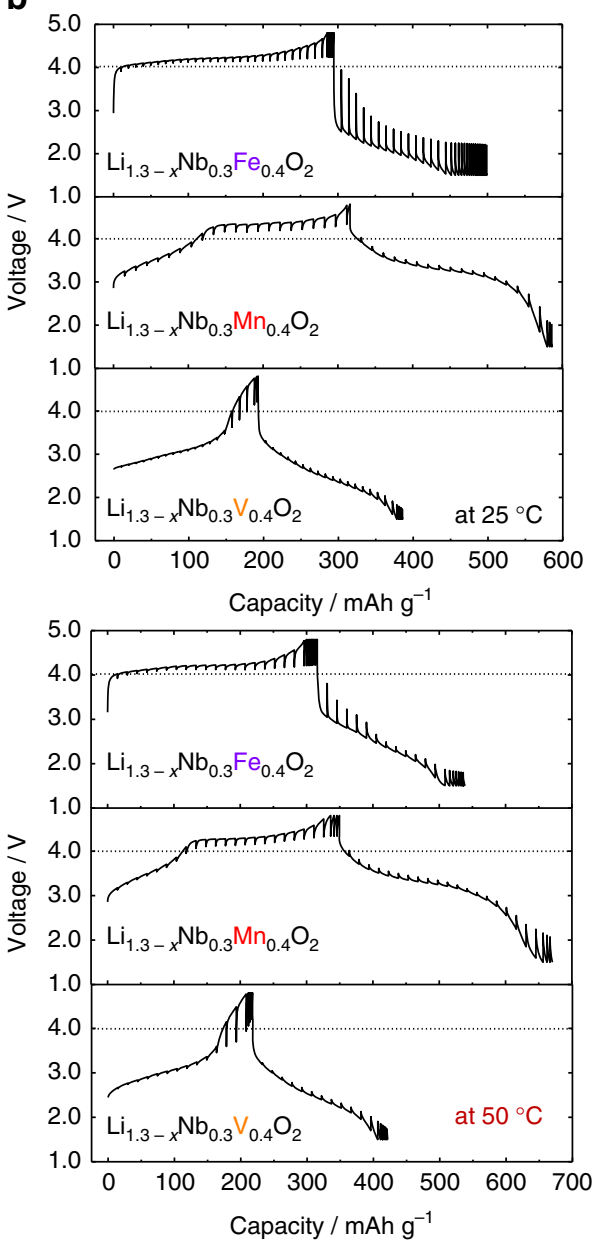

Figure 2 | Electrochemical properties of $\mathbf{L i}_{\mathbf{1 . 3}} \mathbf{N b}_{\mathbf{0 . 3}} \mathbf{M e}_{\mathbf{0 . 4}} \mathbf{O}_{\mathbf{2}}$ in Li cells. (a) Galvanostatic oxidation/reduction curves of $\mathrm{Li}_{1.3} \mathrm{Nb}_{0.3} \mathrm{Me}_{0.4} \mathrm{O}_{2}\left(\mathrm{Me}=\mathrm{Fe}^{3}+\right.$, $\mathrm{Mn}^{3+}$ and $\mathrm{V}^{3+}$ ) samples in Li cells at $10 \mathrm{mAg}^{-1}$ at $50^{\circ} \mathrm{C}$. Quasi open circuit voltage (QOCV) of the samples measured by galvanostatic intermittent titration technique (GITT) is also plotted in (b); charge for $1 \mathrm{~h}$ at $10 \mathrm{mAg}^{-1}$ at room temperature and $50^{\circ} \mathrm{C}$ and rest for $5 \mathrm{~h}$. 
from 3 to $4 \mathrm{~V}$ and slightly large polarization for the plateau region at $4.2 \mathrm{~V}$. On the discharge process, two regions are not distinguished and a continuous S-shaped profile on QOCV is observed. Such behaviour originates from the hysteresis of oxidation/reduction reaction for solid-state redox of oxide ions.

Charge compensation mechanisms in $\mathrm{Li}_{3} \mathrm{NbO}_{4}-\mathrm{LiMeO}_{2}$ system. Three different samples show quite different electrochemical behaviour in Li cells, as shown in Fig. 2. Such behaviour is expected to originate from differences in charge compensation mechanisms depending on the $3 d$ transition metals ( $\mathrm{Fe}, \mathrm{Mn}$ and $\mathrm{V}$ ) in the $\mathrm{Li}_{3} \mathrm{NbO}_{4}$ framework. Charge compensation mechanisms in $\mathrm{Li}$ cells were, therefore, examined using a combination of different characterization methods: synchrotron SXRD, hard/soft X-ray absorption spectroscopy (XAS) and $\mathrm{X}$-ray photoelectron spectroscopy (XPS) with the assist of density functional theory (DFT) calculations. Results are described in detail in Supplementary Figs 3-10, and DFT calculations in Fig. 3, Supplementary Figs 11-15 and Supplementary Table 1.

Important findings are summarized as follows: (1) In the Mn system, reversible oxidation of oxide ions, coupled with $\mathrm{Mn}^{3+}$ / $\mathrm{Mn}^{4+}$ redox, is realized as reported in our previous work ${ }^{20}$. (2) In the $\mathrm{V}$ system, $\mathrm{V}^{3+} / \mathrm{V}^{5}$ two-electron redox is active, but the oxidation of oxide ions is not evidenced. (3) In the Fe system, the formation of superoxide $\left(\mathrm{O}_{2}^{-}\right)$(ref. 29) is observed from the measurement of $\mathrm{O}$ K-edge XAS, which is further supported by the DFT study with COOP analysis (Supplementary Fig. 14). Since the most significant changes on charge/discharge curves were observed for the Fe system, changes in soft XAS spectra were examined on the initial cycle and second charge at $50^{\circ} \mathrm{C}$ (Fig. 4). Formation of superoxide is further pronounced on charge at $50{ }^{\circ} \mathrm{C}$, and superoxide is stabilized in the bulk of particle rather than the surface (Supplementary Fig. 9). However, superoxide species are electrochemically oxidized and decomposed by further charge. The superoxide species disappears as seen in the $\mathrm{O}$ $\mathrm{K}$-edge spectra after charge to $4.8 \mathrm{~V}$. This process inevitably results in the oxygen loss and structural reconstruction process (the latter is also supported by transmission electron microscopy as the formation of nanosize grains, as shown in Fig. 4e). Origin of the formation of superoxide is discussed in the later section. The oxygen loss results in the reduction of $\mathrm{Fe}^{3+}$ to $\mathrm{Fe}^{2+}$ and accumulation of surface deposits on discharge. The voltage plateau is significantly shortened on the second charge, and the S-shaped voltage profile centred at $2.5 \mathrm{~V}$ is observed with relatively small polarization. This reaction mainly originates from $\mathrm{Fe}^{2+} / \mathrm{Fe}^{3+}$ redox, as shown in Fig. $4 \mathrm{~b}$, and the formation of superoxide is not found in the second charge. In the conventional Li-excess system, $\mathrm{Li}_{1+x} \mathrm{Ni}_{y} \mathrm{Co}_{z} \mathrm{Mn}_{(1-x-y-z)} \mathrm{O}_{2}$, a clear voltage plateau is observed at $4.6 \mathrm{~V}$ at the initial charge process, but not for the second charge. An S-shaped voltage profile without the plateau region is observed from the second charge with activated $\mathrm{Mn}^{3+} / \mathrm{Mn}^{4+}$ redox ${ }^{8,9,11,12}$. The reversible contribution of oxide ions for charge compensation is less pronounced in these systems. Oxygen loss on charge is further supported by XPS (Fig. 4f and Supplementary Fig. 8). Oxygen molecules released in the cells are electrochemically reduced on discharge, leading to the formation of superoxide (on the surface

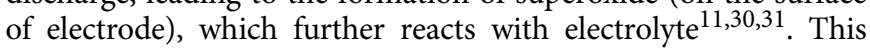
process is clearly evidenced, especially for the Fe system, as the accumulation of surface deposits on $\mathrm{AB}$ and active materials (Fig. 4f and Supplementary Fig. 8).

In contrast, for $\mathrm{Li}_{1.3} \mathrm{Nb}_{0.3} \mathrm{Mn}_{0.4} \mathrm{O}_{2}$, reversible changes in O K-edge XAS spectra are observed (Supplementary Fig. 6). Moreover, a clear voltage plateau is observed even in the 'second' charge (Fig. 2), indicating that solid-state redox reaction is a reversible process. Note that DFT calculations also support these findings. Formation energy of the charged $\mathrm{Mn}$ system is energetically stable, but segregation (decomposition) to $\mathrm{LiFeO}_{2}$ and $\mathrm{LiNbO}_{3}$ accompanying $\mathrm{O}_{2}$ gas evolution is energetically preferable for the Fe system (see equations (s3) and (s4) in Supplementary Methods). Nevertheless, the plateau gradually becomes shorter in the continuous cycles probably because of the increase in polarization. Cyclability as the electrode material is expected to be further improved through the optimization of battery components, for example, electrolyte, binder, surface coating of particle and so on, and controlling charge conditions, as shown in our previous work ${ }^{20}$.

A question remains in the $\mathrm{V}$ system. Why are not oxide ions experimentally oxidized in this system? Theoretical prediction in Fig. 3 indicates that (1) two-electron redox of $\mathrm{V}^{3+} / \mathrm{V}^{5+}$ occurs coupled with vanadium migration to tetrahedral sites, which is consistent with experimental finding (see the Supplementary Methods for theoretical and experimental evidences) and (2) oxidation of oxide ions is also possible in the $\mathrm{V}$ system, which was not experimentally observed on charge to $4.8 \mathrm{~V}$, as shown in Fig. 2. This inconsistency for the oxide ion redox simply originates from the difficultly of the electron transfer from oxide ions to $\mathrm{V}^{5+}$ for the fully charged state, namely kinetic limitation. DFT calculation clearly supports this fact. Oxide ions are theoretically oxidized, but the hole induced in oxygen $2 p$ orbital is isolated in the structure, as shown in Fig. 3. Vanadium ions in $\mathrm{Li}_{0.5} \mathrm{Nb}^{5}+{ }_{0.3} \mathrm{~V}^{5}+{ }_{0.4} \mathrm{O}_{2}$ (fully charged state), therefore, cannot transfer electrons from oxide ions and oxidation of oxide ions in the $\mathrm{V}$ system is kinetically restricted. Similar situation is observed for $\mathrm{Li}_{3}{ }_{x} \mathrm{NbO}_{4}$ as a model material. Calculated voltage by DFT study is estimated to be $4.8 \mathrm{~V}$ for $\mathrm{Li}_{3} \mathrm{NbO}_{4}\left(\mathrm{Li}_{3 / 2} \mathrm{Nb}_{1 / 2} \mathrm{O}_{2}\right.$, Fig. 3a). Corresponding partial density of states diagram and partial electron density are also shown in Supplementary Fig. 15. Oxidation of $\mathrm{O}^{2}-$ ions is indicated during delithiation by DFT study since creation of $\mathrm{O} 2 p$ hole level is clearly visible just above

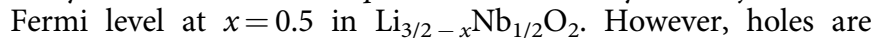
completely isolated in the structure, and thus electron transfer between $\mathrm{O} 2 p$ and $\mathrm{Nb}^{5}+$ is kinetically limited as observed in the experimental study ${ }^{20}$.

Design of high-capacity electrode materials with anion redox. As shown in this article, oxidation of oxide ions is not difficult, and only electron transfer from oxide ions to $3 d$ transition metals is a necessary condition. However, the stabilization of oxidation reaction of oxide ions is not easy. In many materials, oxidation of oxide ions is possible, but this process induces oxygen loss, as in the cases of $\mathrm{Li}_{2} \mathrm{MnO}_{3}$ (ref. 4), $\mathrm{Li}_{4} \mathrm{FeSbO}_{6}$ (ref. 32), $\mathrm{Li}_{4} \mathrm{NiMoO}_{6}$ (ref. 22) and so on ${ }^{8,24}$. The reversible contribution of oxide ions for charge compensation has been reported only in limited electrode materials, for example, $\mathrm{Li}_{2} \mathrm{Ru}_{1-y} \mathrm{Me}_{y} \mathrm{O}_{3}(\mathrm{Me}=\mathrm{Ru}, \mathrm{Sn}$ and $\mathrm{Ti}$ ) (refs 14,33), and the Nb-Mn system shown in this study. In general, peroxide/superoxide species are stabilized for $\mathrm{sp}$ elements without valence electrons $\left(\mathrm{K}^{+}, \mathrm{Ca}^{2+}\right.$ and so on $)$ and $\mathrm{d}^{10}$ closed-shell $\left(\mathrm{Zn}^{2+}, \mathrm{Cd}^{2+}\right.$ and so on). In contrast, transition metal oxides often decompose these species. One typical example is a disproportionation reaction of $\mathrm{H}_{2} \mathrm{O}_{2}$ catalysed by $\mathrm{MnO}_{2}$. This reaction is triggered by electron transfer between peroxide ions and surface manganese ions. $\mathrm{Nb}^{5+}$ also has no valence electron, and therefore a similar role is anticipated with the sp elements. Among $3 d$ transition metal elements, $\mathrm{Ti}^{4+}$ has a similar electronic configuration with $\mathrm{Nb}^{5+}$. These ions most probably screen off electrons of unstable 'oxidized' oxide ions and thus suppresses charge transfer. In addition, $\mathrm{Nb}^{5+}$ and $\mathrm{Ti}^{4+}$ are highly ionized ions compared with late transition metal ions with oxide ions, and thus the mixing between metal $d$ orbital and 

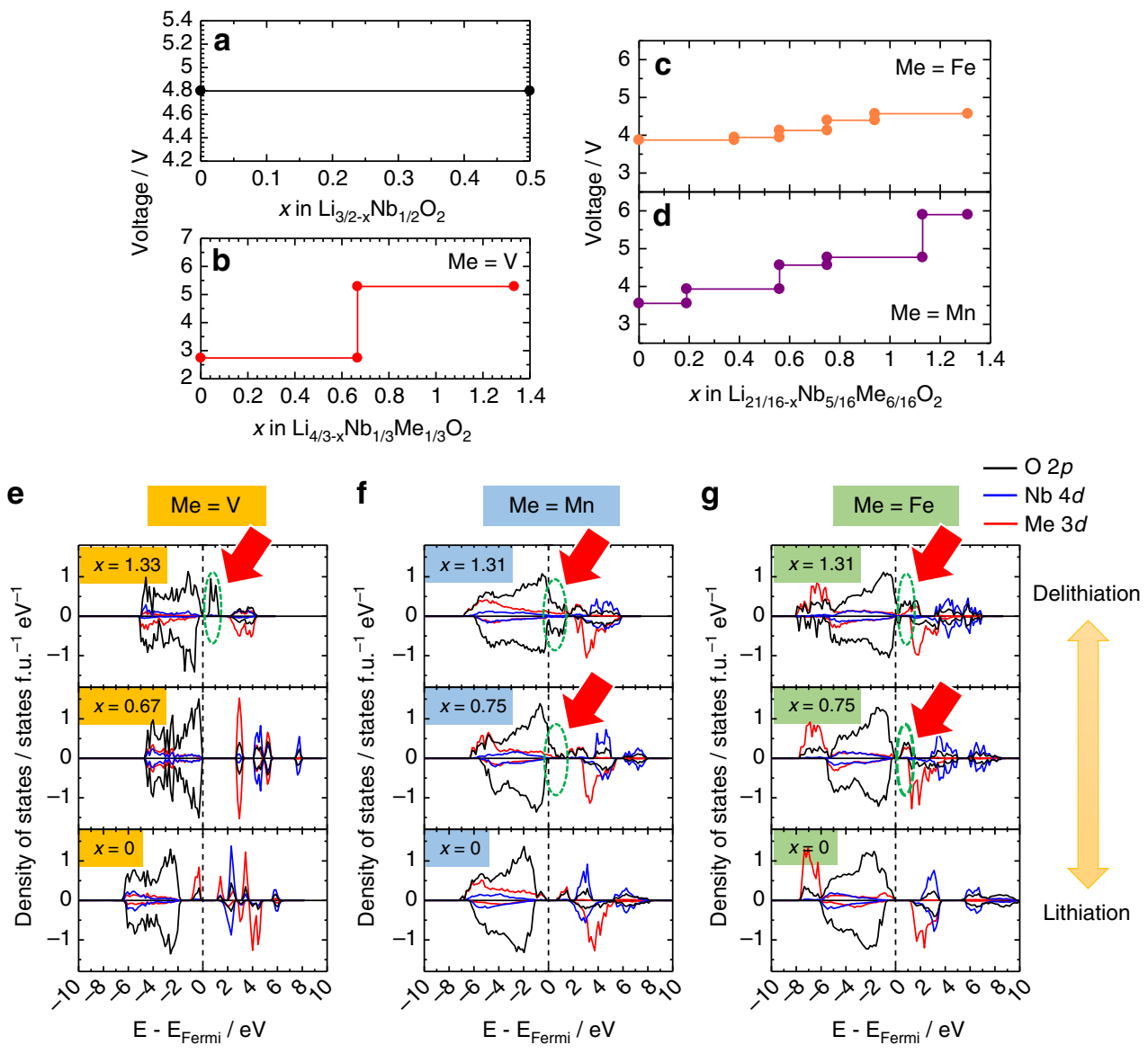

h
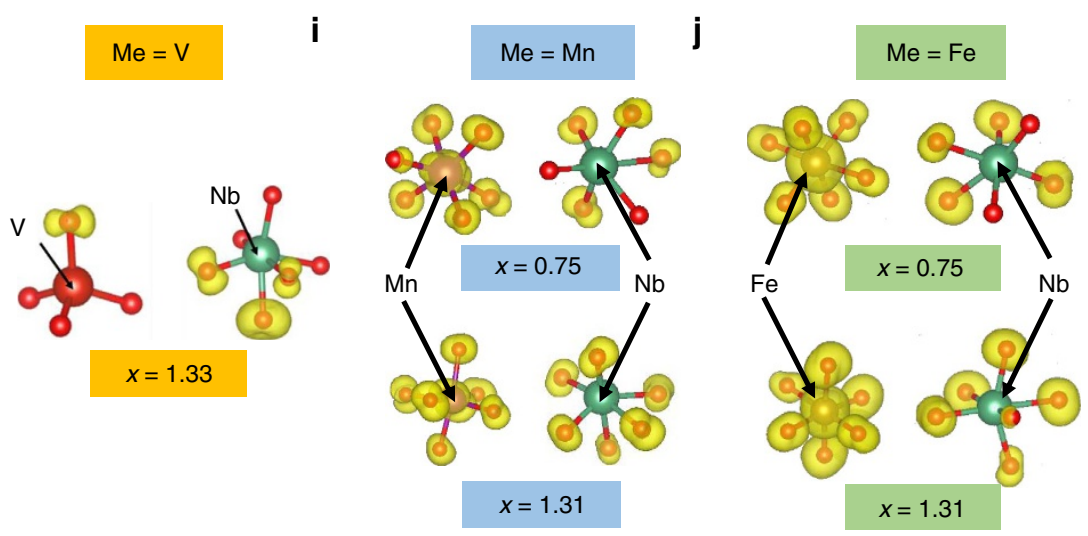

Figure 3 | Summary of DFT calculations for Li-Nb-Me-O system. Calculated voltage profiles for (a) $\mathrm{Li}_{3} \mathrm{NbO}_{4}\left(\mathrm{Li}_{1.5} \mathrm{NbO}_{2}\right),(\mathbf{b}) \mathrm{Li}_{4 / 3} \mathrm{~V}_{1 / 3} \mathrm{Nb}_{1 / 3} \mathrm{O}_{2}$,

(c) $\mathrm{Li}_{21 / 16-x} \mathrm{Fe}_{6 / 16} \mathrm{Nb}_{5 / 16} \mathrm{O}_{2}$ and (d) $\mathrm{Li}_{21 / 16-x} \mathrm{Mn}_{6 / 16} \mathrm{Nb}_{5 / 16} \mathrm{O}_{2}$, and partial density of states (PDOS) are also shown in e-g. PDOS of $\mathrm{Li}_{3}-x \mathrm{NbO}_{4}$ is shown in Supplementary Fig. 15. Transition metal ions are mainly oxidized at an early stage of Li removal, whereas oxide ions are responsible for charge compensation at a late stage. The highest voltage is seen for $\mathrm{M}=\mathrm{Fe}$, followed in order by $\mathrm{Mn}$ and $\mathrm{V}$, at an early stage of Li removal. Fe $3 d$ orbital strongly hybridized with $O 2 p$ orbital at $x=0.75$ while weak hybridization is observed for the Mn system. $\vee 3 d$ orbital is localized at above $O 2 p$ level. These are supported by the PDOS diagrams and calculated partial charge density of electron at the hole state near to Fermi level, as shown in $\mathbf{h}-\mathbf{j}$ ).

oxygen $2 p$ orbital is less pronounced. Therefore, similar to the lithium enrichment ${ }^{18,19}$, a character of oxide ions becomes more ionic (approaches two minus as a net charge) because of electron donation from $\mathrm{Nb}$ and $\mathrm{Ti}$, and this fact would be beneficial to stabilize the oxidation of oxide ions.

To test this hypothesis, a binary system of $\mathrm{Li}_{2} \mathrm{TiO}_{3}-\mathrm{LiMnO}_{2}$ has been examined. One to one composition between $\mathrm{Li}_{2} \mathrm{TiO}_{3}$ and $\mathrm{LiMnO}_{2}$ has been synthesized, which is reformulated as $\mathrm{Li}_{1.2} \mathrm{Ti}_{0.4} \mathrm{Mn}_{0.4} \mathrm{O}_{2}$. A mole fraction of $\mathrm{Mn}$ was adjusted to be the same with $\mathrm{Li}_{1.3} \mathrm{Nb}_{0.3} \mathrm{Mn}_{0.4} \mathrm{O}_{2}$. Similar to $\mathrm{Li}_{3} \mathrm{NbO}_{4}$, the cationdisordered rocksalt phase is obtained for $\mathrm{Li}_{1.2} \mathrm{Ti}_{0.4} \mathrm{Mn}_{0.4} \mathrm{O}_{2}$ as a single phase, and uniform size $(2-3 \mu \mathrm{m})$ of primary particles is found by SEM (Supplementary Fig. 16). A result of structural analysis by neutron scattering is also provided in Fig. 5a and Supplementary Table 2. A mole fraction of $\mathrm{Li}$ in the cationdisordered rocksalt phase is inevitably lowered by the use of $\mathrm{Ti}^{4+}$. This fact results in the increase in penalty for percolating $\mathrm{Li}$ migration in the structure 27,34 . However, percolation probability of electron migration through the bonding between oxide ions and manganese ions ( $40 \%$ in the structure) is comparable with that of $\mathrm{Li}_{1.3} \mathrm{Nb}_{0.3} \mathrm{Mn}_{0.4} \mathrm{O}_{2} . \mathrm{Li}_{1.2} \mathrm{Ti}_{0.4} \mathrm{Mn}_{0.4} \mathrm{O}_{2}$ was mixed with $10 \mathrm{wt} \%$ acetylene black (HS-100, Denka Co. Ltd) and ball-milled 
a

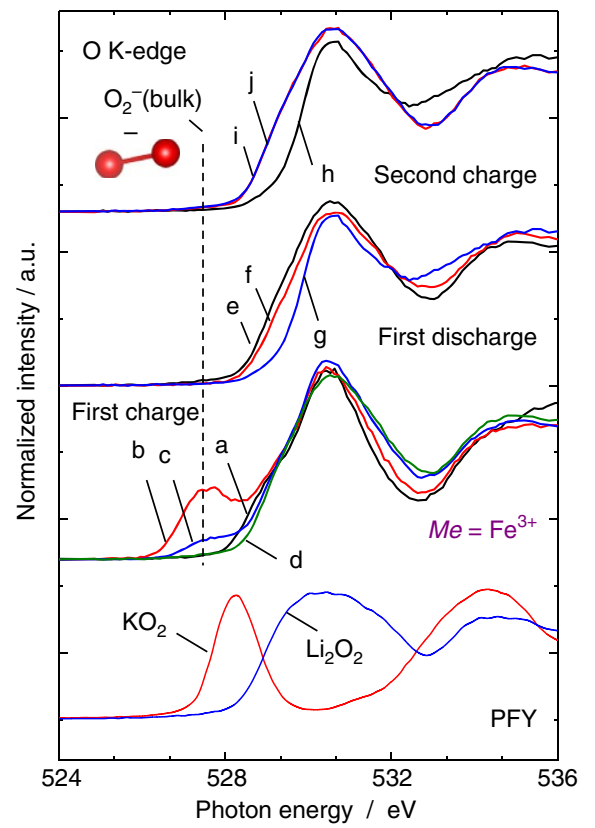

b

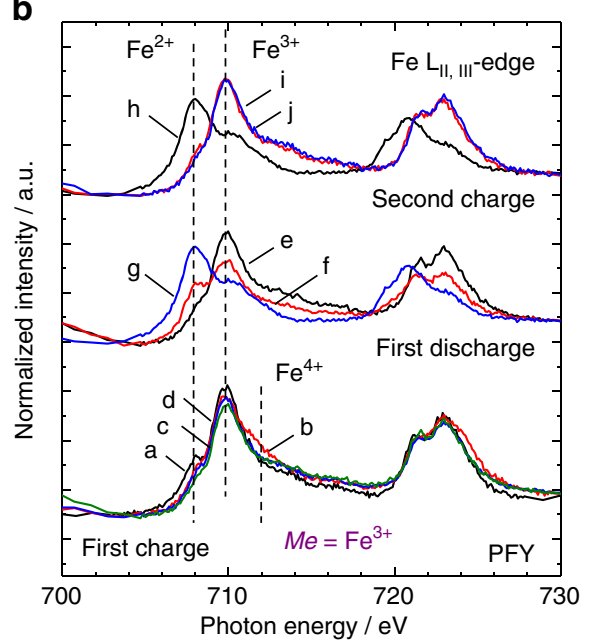

C

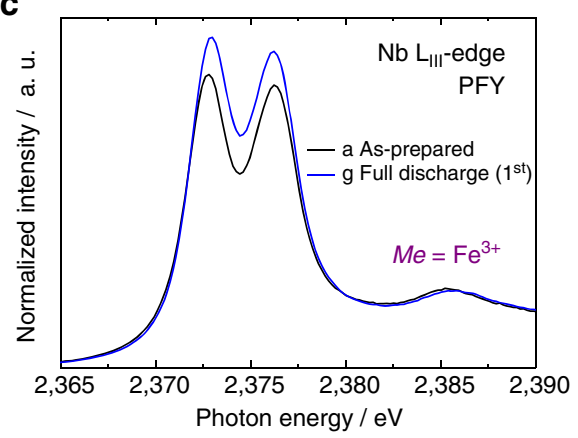

d

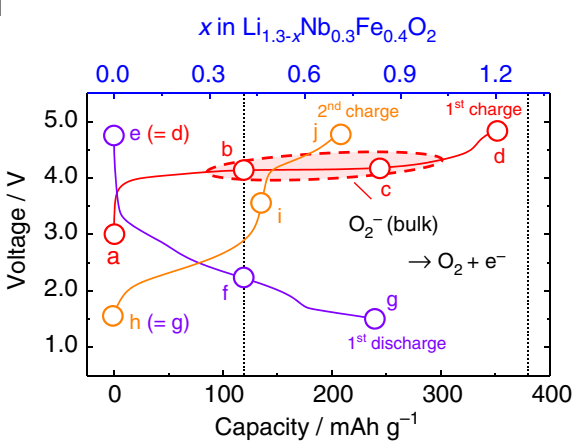

e
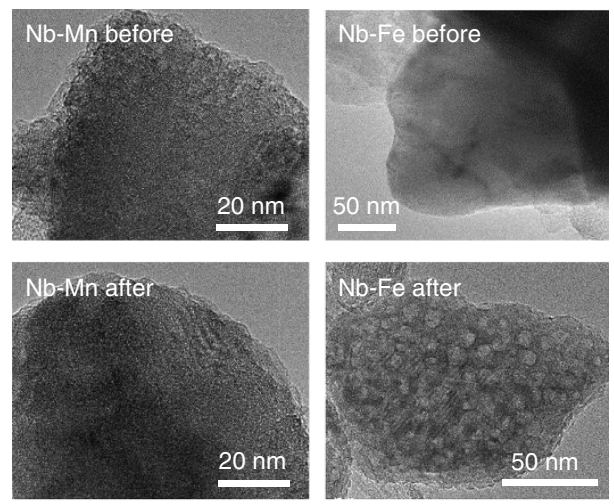

Nb-Fe after
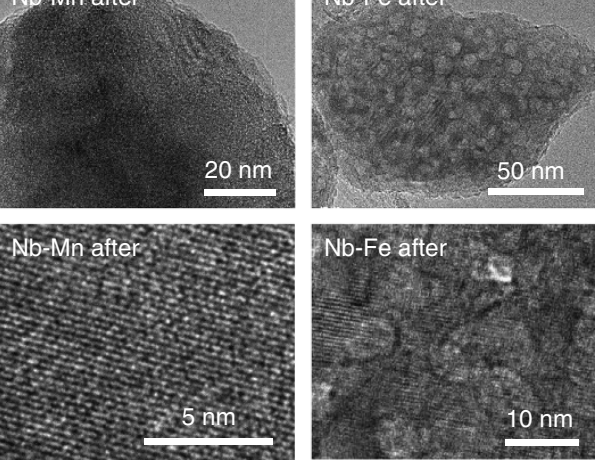

f

$\mathrm{O}_{2}^{-}$(surface) + electrolyte

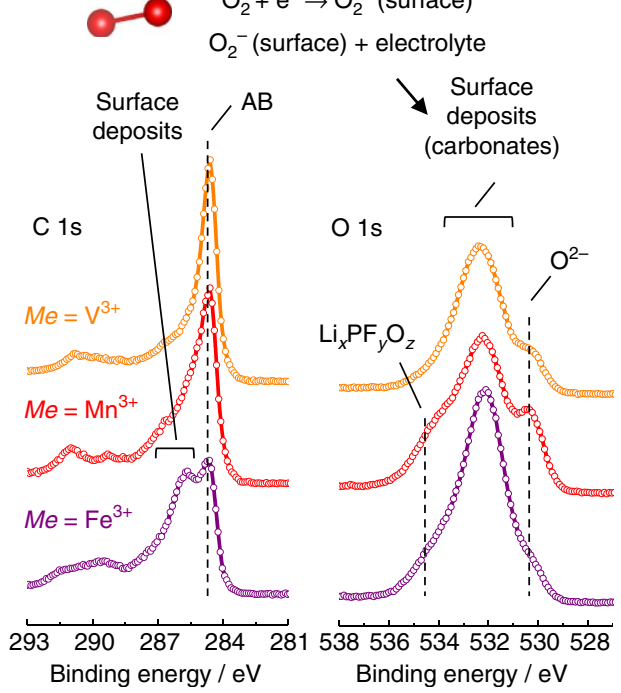

Figure 4 | Changes in electronic structures for $\mathbf{L i}_{1.3}{ }_{-} \mathbf{N b}_{\mathbf{0 . 3}} \mathbf{F e}_{\mathbf{0 . 4}} \mathbf{O}_{\mathbf{2}}$ on initial charge/discharge and second charge. Changes in the $\mathrm{O} \mathrm{K}$-edge (a) Fe $\mathrm{L}_{11}$, III-edge XAS spectra (b), Nb LIII-edge XAS spectra (c), and the points where XAS spectra have been collected in (d). XAS spectra of KO $\mathrm{KO}_{2}$ (superoxide) and $\mathrm{Li}_{2} \mathrm{O}_{2}$ (peroxide) are also shown in (a) for comparison. Niobium is not responsible for charge compensation process (other data sets of $\mathrm{Nb}$ are shown in Supplementary Fig. 10). (e) TEM images of $\mathrm{Li}_{1.3} \mathrm{Nb}_{0.3} \mathrm{Fe}_{0.4} \mathrm{O}_{2}$ and $\mathrm{Li}_{1.3} \mathrm{Nb}_{0.3} \mathrm{Mn}_{0.4} \mathrm{O}_{2}$ particles before and after the electrochemical cycle at $50{ }^{\circ} \mathrm{C}$. Oxygen loss for the Fe system results in the formation of nanosized grains in the single particle, and not for the Mn system. Lattice fringes are clearly observed after electrochemical cycle for the Mn system. (f) Surface structures observed by X-ray photoelectron (XPS) spectroscopy after discharge to $1.5 \mathrm{~V}$. Oxygen molecules released on charge result in the electrochemical reduction on discharge, leading to the formation of surface deposits because of chemical reaction between active superoxide with electrolyte, as shown in our previous literature ${ }^{11}$. 


\section{a}

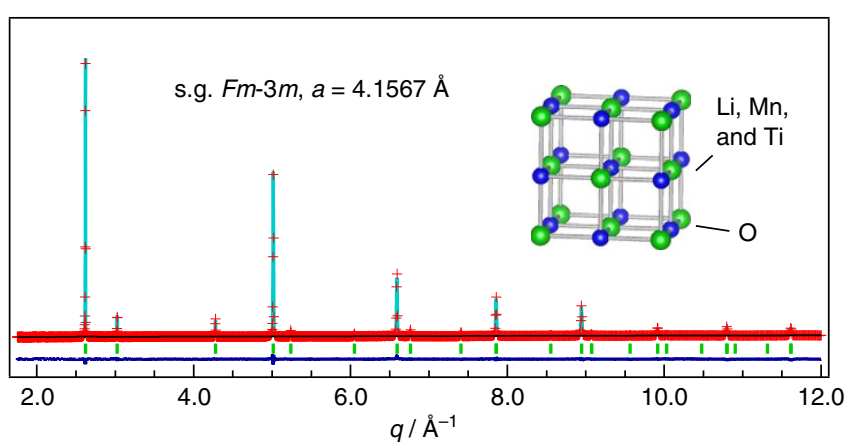

b

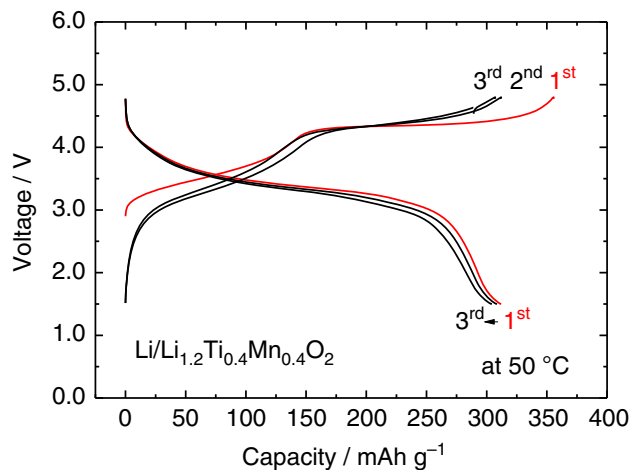

C

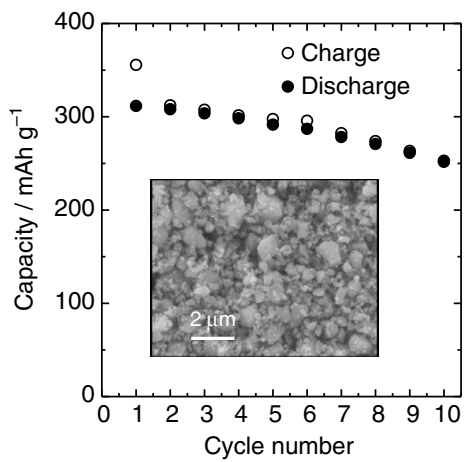

d

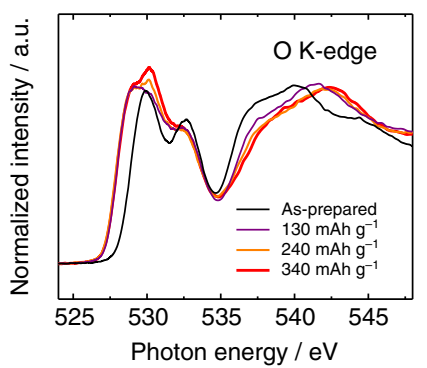

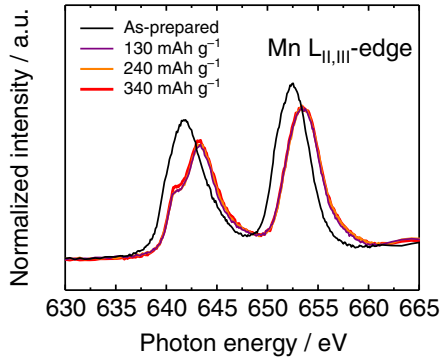

Figure $\mathbf{5}$ | $\mathbf{L i}_{\mathbf{1 . 2}} \mathbf{T i}_{\mathbf{0 . 4}} \mathbf{M n}_{\mathbf{0 . 4}} \mathbf{O}_{\mathbf{2}}$ with a cation disordered rocksalt structure. (a) Neutron diffraction pattern of the as-prepared sample; (b) charge/discharge curves in a Li cell at a rate of $5 \mathrm{~mA} \mathrm{~g}^{-1}$ at $50^{\circ} \mathrm{C}$; (c) discharge capacity retention and an SEM image of the ball-milled sample and (d) changes in O K-edge and $M n L_{l 1}, \ldots$-edge XAS spectra on charge in Li cells. The samples used in (d) were prepared at $50^{\circ} \mathrm{C}$ in Li cells.

to enhance the electrode performance. Thus prepared sample shows a large reversible capacity, as shown in Fig. 5b, and the Nb-free sample delivers more than $300 \mathrm{mAhg}^{-1}$ at $50{ }^{\circ} \mathrm{C}$. A voltage profile of $\mathrm{Li}_{1.2-x} \mathrm{Ti}_{0.4} \mathrm{Mn}_{0.4} \mathrm{O}_{2}$ quite resembles that of $\mathrm{Li}_{1.3-x} \mathrm{Nb}_{0.3} \mathrm{Mn}_{0.4} \mathrm{O}_{2}$. Available energy density of $\mathrm{Li}_{1.2-x} \mathrm{Ti}_{0.4} \mathrm{Mn}_{0.4} \mathrm{O}_{2}$ exceeds $1,000 \mathrm{mWhg}^{-1}$ as a positive electrode material. Capacity retention is much better than that of pure $\mathrm{Li}_{2} \mathrm{MnO}_{3}$ (ref. 35) and slightly improved in comparison to $\mathrm{Li}_{1.3-{ }_{x}} \mathrm{Nb}_{0.3} \mathrm{Mn}_{0.4} \mathrm{O}_{2}$, as shown in Fig. 5c. To examine whether oxide ions are oxidized and stabilized in $\mathrm{Li}_{1.2-x} \mathrm{Ti}_{0.4} \mathrm{Mn}_{0.4} \mathrm{O}_{2}$, reaction mechanisms were examined by soft XAS with fluorescence yield in the synchrotron facility ${ }^{36}$. On the initial charge, $\mathrm{Mn}^{3+}$ is oxidized to $\mathrm{Mn}^{4+}$ for the slope region to $4 \mathrm{~V}$ as evidenced from Mn L-edge XAS spectra, and this fact also influences the profile of O K-edge XAS spectra (Fig. 5d). No change in Mn L-edge XAS spectra is observed for the plateau region at $4.2 \mathrm{~V}$. A change in electronic structures is also not evidenced for Ti L-edge XAS spectra (Supplementary Fig. 17).

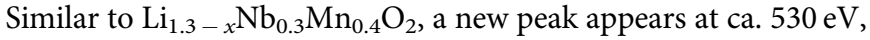
(see Supplementary Fig. 6 for more details), which is further intensified as increase in the charge capacity for the plateau region, and the formation of superoxide is not evidenced. Similar observation is also noted for the recent study for the conventional Li-excess system ${ }^{18}$, but the change is more clearly pronounced in the Ti-Mn system. Although the energy of the new peak is consistent with that of $\mathrm{Li}_{2} \mathrm{O}_{2}$, further study is needed to understand the factor affecting the profile of XAS spectra. Nevertheless, the possibility of the formation of superoxide species can be excluded. Such change potentially originates from two possibilities: the formation of isolated holes ${ }^{18,19}$ and/or $\sigma$-hybridization as theoretically proposed in the $\mathrm{Ru}-\mathrm{Sn}$ system after delithiation ${ }^{19}$. An almost identical profile with the pristine sample is observed after discharge to $1.5 \mathrm{~V}$, suggesting the reversible process. Very recently, electrode performance and changes in $\mathrm{O} \mathrm{K}$-edge XAS spectra on charge have been reported for $\mathrm{Li}_{1.19} \mathrm{Ti}_{0.38} \mathrm{Fe}_{0.57} \mathrm{O}_{2}$ (ref. 37) and $\mathrm{Li}_{1.42} \mathrm{Mo}_{0.29} \mathrm{Fe}_{0.29} \mathrm{O}_{2}$ (ref. 38). Similar to $\mathrm{Li}_{1.3-}{ }_{x} \mathrm{Nb}_{0.3} \mathrm{Fe}_{0.4} \mathrm{O}_{2}$ clear evidence for the formation of superoxide and large polarization on charge/discharge have been reported for both samples.

The selection of $3 d$ transition metals, which accept electrons from oxide ions on charge, is an essential key to determine whether to stabilize oxidation of oxide ions (the formation and stabilization of isolated holes as proposed in the literature ${ }^{18,19}$ ) or to form unstable superoxide-like species. Stabilization/ 

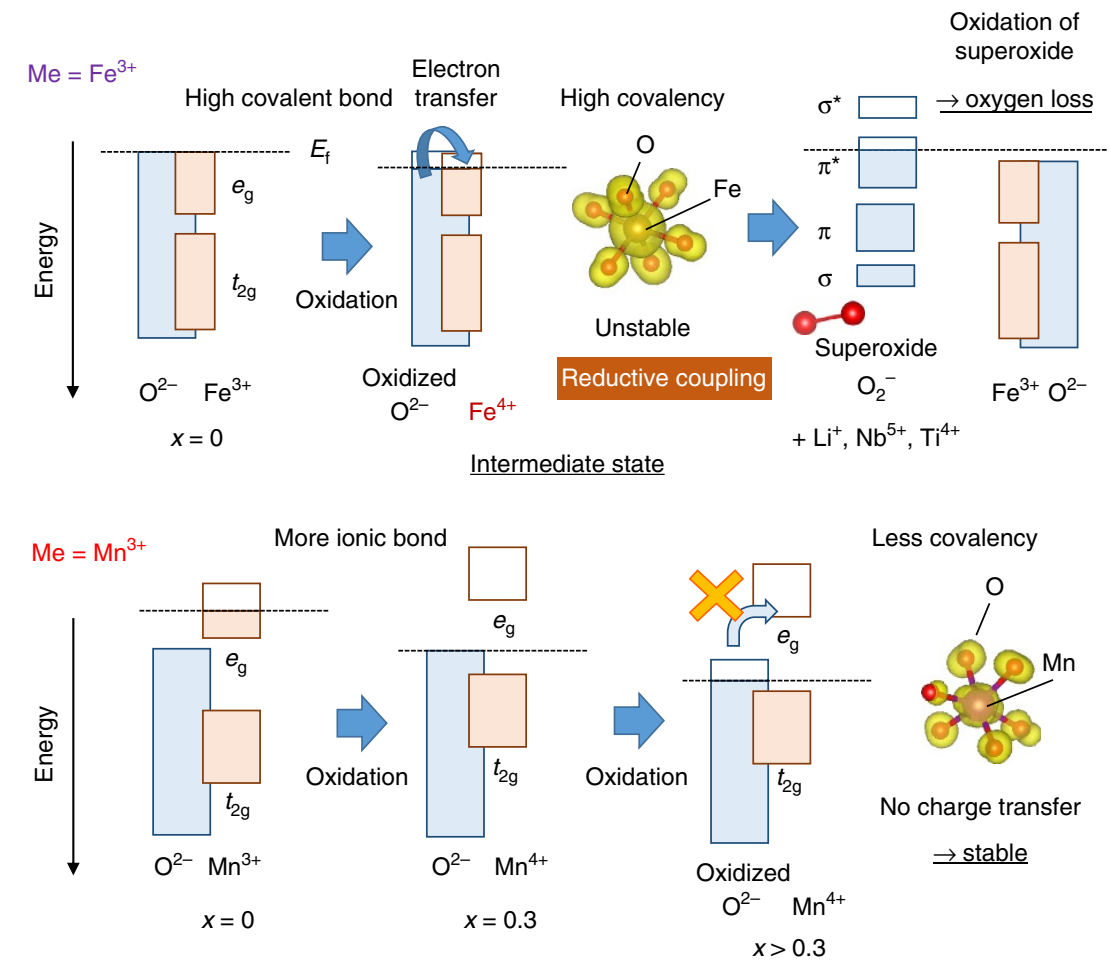

Figure 6 | Proposed stabilization/destabilization mechanisms for solid-state redox reaction of oxide ions. Charge compensation mechanisms on charge in $\mathrm{Li}$ cells are compared for $\mathrm{Li}_{1.3-x} \mathrm{Nb}_{0.3} \mathrm{Me}_{0.4} \mathrm{O}_{2}\left(\mathrm{Me}=\mathrm{Fe}^{3+}\right.$ and $\mathrm{Mn}^{3+}$ ). A similar stabilization mechanism is anticipated for $\mathrm{Li}_{1.2}-\mathrm{Ti}_{0.4} \mathrm{Mn}_{0.4} \mathrm{O}_{2}$.

destabilization mechanisms for $\mathrm{Mn} / \mathrm{Fe}$ are proposed in Fig. 6. For the case of $\mathrm{Nb}(\mathrm{Ti})-\mathrm{Fe}$, the DFT data in Fig. 3 suggest that both oxide and iron ions are simultaneously oxidized on charge (namely oxidation of high covalent $\mathrm{Fe}-\mathrm{O}$ bond). However, only trace amount of $\mathrm{Fe}^{4+}$ is experimentally found in the Fe L-edge spectra. This fact suggests that electron transfer occurs from 'oxidized' oxide ions (or a hole induced in $\mathrm{O} 2 p$ ) to $\mathrm{Fe}^{4+}$ because energy levels of both ions are similar for each other, namely highly covalent. Electrons are donated from oxidized oxide ions to neighbouring $\mathrm{Fe}^{4+}$ ions, leading to the formation of superoxide and $\mathrm{Fe}^{3+}$. This process is also called as the reductive coupling ${ }^{14,16}$. The formation of superoxide is further supported by the DFT study with COOP analysis (Supplementary Fig. 14). Such superoxide species would be stabilized by coupling with $\mathrm{Li}^{+}$and $\mathrm{Nb}^{5+}\left(\mathrm{Ti}^{4+}\right)$ ions. Similar results are expected for $\mathrm{Ni}^{3+/ 4+}$ and $\mathrm{Co}^{3+/ 4+}$ with heavily hybridized characters for oxide ions near the Fermi level and indeed oxygen loss is experimentally observed for Li-excess electrode materials with these elements. In contrast, oxide ions do not donate electrons to less covalent $\mathrm{Mn}^{4+}$ with the $d^{3}$ configuration (as the high-spin configuration) associated with energy gap between filled $t_{2 \mathrm{~g}}$ and empty $e_{\mathrm{g}}$ bands, as shown in Figs 3 and $6 . \mathrm{Ru}^{5+}$ also have a similar electronic configuration. Since the energy level of $t_{2 g}$ orbital for $\mathrm{Mn}^{4+}$ is high enough than that of Fermi level, oxide ions are solely oxidized on further oxidation. The presence of electrons in $t_{2 g}$ orbital is also essential without the sacrifice of electronic conductivity in bulk. Moreover, this reaction is further stabilized by the presence of $\mathrm{Nb}^{5+}$ and $\mathrm{Ti}^{4+}$, which donates electrons to oxide ions because of high ionic characters as cations and completely suppresses charge transfer from oxidized oxide ions.

In conclusion, the use of solid-state redox reaction of oxide ions is an effective strategy to further increase energy density of LIBs. We have demonstrated that the stabilization of redox reaction for oxide ions is possible using a combination of only $3 d$ transition metals as the metallic constituents. This serves as a significant proof-of-concept towards practical applications. We expect that by relaxing the constraints posed on materials design by the conventional concept of transition metal redox, many new positive electrode materials with high capacity will appear, similar to $\mathrm{Li}_{1.2} \mathrm{Ti}_{0.4} \mathrm{Mn}_{0.4} \mathrm{O}_{2}$.

\section{Methods}

Synthesis of materials. $\mathrm{Li}_{3} \mathrm{NbO}_{4}$ was prepared by solid-state reaction from stoichiometric amounts of $\mathrm{Li}_{2} \mathrm{CO}_{3}$ (> 98.5\%; Kanto Kagaku) and $\mathrm{Nb}_{2} \mathrm{O}_{5}$ (99.9\%; Wako Pure Chemical Industries) at $950{ }^{\circ} \mathrm{C}$ for $24 \mathrm{~h}$ in air. $\mathrm{Li}_{1.3} \mathrm{Nb}_{0.3}$ $\mathrm{Me}_{0.4} \mathrm{O}_{2}\left(\mathrm{Me}=\mathrm{Fe}^{3+}, \mathrm{Mn}^{3+}\right.$ and $\left.\mathrm{V}^{3+}\right)$ samples were prepared from $\mathrm{Li}_{2} \mathrm{CO}_{3}$, $\mathrm{Nb}_{2} \mathrm{O}_{5}$ and precursors containing each transition metal: $\mathrm{Mn}_{2} \mathrm{O}_{3}, \mathrm{Fe}_{2} \mathrm{O}_{3}$ (99.9\%; Wako Pure Chemical Industries), $\mathrm{V}_{2} \mathrm{O}_{3}$ (98\%; Sigma-Aldrich Japan). $\mathrm{Mn}_{2} \mathrm{O}_{3}$ was obtained by heating of $\mathrm{MnCO}_{3}$ (Kishida Chemical) at $700{ }^{\circ} \mathrm{C}$ for $12 \mathrm{~h}$. The precursors were thoroughly mixed by wet mechanical ball milling and then dried in air. Thus obtained mixtures of the samples were pressed into pellets. The pellets were heated at $900{ }^{\circ} \mathrm{C}$ for $12 \mathrm{~h}$ in air $\left(\mathrm{Fe}^{3+}\right)$ or inert atmosphere $\left(\mathrm{Mn}^{3+}\right.$ and $\left.\mathrm{V}^{3+}\right)$. The samples were stored in an Ar-filled glove box until use.

$\mathrm{Li}_{1.2} \mathrm{Ti}_{0.4} \mathrm{Mn}_{0.4} \mathrm{O}_{2}$ was prepared from $\mathrm{Li}_{2} \mathrm{CO}_{3}, \mathrm{TiO}_{2}$ (Anatase, 98.5\%; Wako Pure Chemical Industries), and $\mathrm{Mn}_{2} \mathrm{O}_{3}$. The precursors were thoroughly mixed by wet mechanical ball milling and the mixture was heated at $900^{\circ} \mathrm{C}$ for $12 \mathrm{~h}$ in inert atmosphere. Particle morphology of the samples was observed using a scanning electron microscope (JCM-6000, JEOL) with acceleration voltage of $15 \mathrm{keV}$.

Electrochemical characterization. Electrode performance of the samples was examined for the carbon composite samples prepared by ball-milling. As-prepared $\mathrm{Li}_{1.3} \mathrm{Nb}_{0.3} \mathrm{Me}_{0.4} \mathrm{O}_{2}\left(\mathrm{Me}=\mathrm{Fe}^{3+}, \mathrm{Mn}^{3+}\right.$ and $\left.\mathrm{V}^{3+}\right)$ were mixed with acetylene black by using a planetary ball mill (PULVERISETTE 7; FRITSCH) at 300 r.p.m with a zirconia container and balls. The samples used in Fig. 2, Supplementary Figs 2 and 8 were mixed with $10 \mathrm{wt} \%$ carbon. Composite electrodes consisted of $76.5 \mathrm{wt} \%$ active materials, $13.5 \mathrm{wt} \%$ acetylene black and $10 \mathrm{wt} \%$ poly(vinylidene fluoride), pasted on aluminium foil as a current collector. Rest of the data were collected using the samples with $20 \mathrm{wt} \%$ carbon. Composite electrodes consisted of $72 \mathrm{wt} \%$ active materials, $18 \mathrm{wt} \%$ acetylene black and $10 \mathrm{wt} \%$ poly(vinylidene fluoride). Metallic lithium (Honjo Metal) was used as a negative electrode. The electrolyte solution used was $1.0 \mathrm{~mol} \mathrm{dm}^{-3} \mathrm{LiPF}_{6}$ dissolved in ethylene carbonate:dimethyl carbonate (1:1 by volume) (Kishida Chemical). A polyolefin microporous membrane was used as a separator. R2032-type coin cells (Hosen Corp.) or TJ-AC (Tomcell Japan) were assembled in the Ar-filled glove box. The cells were cycled at a rate of $10 \mathrm{mAg}^{-1}$ at room temperature or $50^{\circ} \mathrm{C}$. 
Materials characterization. Soft X-ray absorption (XAS) spectra were collected at BL-11 (O K-edge and $\mathrm{Me} \mathrm{L}_{\mathrm{II}}$,II-edges) in the synchrotron facility of Ritsumeikan University (Synchrotron Radiation Center) ${ }^{36}$. The absorption spectra were collected with fluorescence yield and electron yield modes. Similar to the measurements for hard XAS, the samples were prepared in the Ar-filled glove box, and thus prepared samples were set on the spectrometer using a laboratory-made transfer vessel without air exposure. Normalization of the XAS spectra was carried out using the program code IFEFFIT (ref. 39). The postedge background was determined using a cubic spline procedure.

XPS measurements were carried out with VG ESCALAB 250 spectrometer (Thermo Fisher Scientific K.K.) using monochromatized $\mathrm{Al} \mathrm{K} \alpha$ X-ray radiation $(1486.6 \mathrm{eV})$. The system was operated at $15 \mathrm{kV}$ and $200 \mathrm{~W}$. The base pressure of the analysis chamber was less than $10^{-8} \mathrm{~Pa}$. These characterizations were carried our using a laboratory-made transfer vessel to avoid the sample exposure to moisture/air.

transmission electron microscopy observation was conducted by using JEM-ARM200F (JEOL) operated at $200 \mathrm{keV}$. The samples were dispersed in dimethyl carbonate and then supported on a copper grid.

A neutron diffraction pattern was collected at BL09 (SPICA) in the Material and Life science Facility (MLF) of the Japan Proton Accelerator Research Complex (J-PARC) (ref. 40).

Data availability. The data supporting the main findings of this study are available from the corresponding authors on request.

\section{References}

1. Dunn, B., Kamath, H. \& Tarascon, J.-M. electrical energy storage for the grid: a battery of choices. Science 334, 928-935 (2011).

2. Mizushima, K., Jones, P. C., Wiseman, P. J. \& Goodenough, J. B. $\mathrm{LI}_{X} \mathrm{COO}_{2}$ $(0<x \leq 1)$ - a new cathode material for batteries of high-energy density. Mater. Res. Bull. 15, 783-789 (1980).

3. Ohzuku, T. \& Makimura, Y. Layered lithium insertion material of $\mathrm{LiNi}_{1 / 2}$ $\mathrm{Mn}_{1 / 2} \mathrm{O}_{2}$ : a possible alternative to $\mathrm{LiCoO}_{2}$ for advanced lithium-ion batteries. Chem. Lett. 30, 744-745 (2001).

4. Robertson, A. D. \& Bruce, P. G. Mechanism of electrochemical activity in $\mathrm{Li}_{2} \mathrm{MnO}_{3}$. Chem. Mater. 15, 1984-1992 (2003).

5. Lu, Z. H., MacNeil, D. D. \& Dahn, J. R. Layered cathode materials $\mathrm{Li}\left[\mathrm{Ni}_{x} \mathrm{Li}(1 / 3-2 x / 3) \mathrm{Mn}_{(2 / 3-x / 3)}\right] \mathrm{O}_{2}$ for lithium-ion batteries. Electrochem. Solid State Lett. 4, A191-A194 (2001)

6. Lu, Z. H. \& Dahn, J. R. Understanding the anomalous capacity of $\mathrm{Li} / \mathrm{Li}\left[\mathrm{Ni}_{x} \mathrm{Li}_{(1 / 3-2 x / 3)} \mathrm{Mn}_{(2 / 3-x / 3]} \mathrm{O}_{2}\right.$ cells using in situ X-ray diffraction and electrochemical studies. J. Electrochem. Soc. 149, A815-A822 (2002).

7. Johnson, C. S. et al. The significance of the $\mathrm{Li}_{2} \mathrm{MnO}_{3}$ component in 'composite' $x \mathrm{Li}_{2} \mathrm{MnO}_{3}$ center dot (1-x) $\mathrm{LiMn}_{0.5} \mathrm{Ni}_{0.5} \mathrm{O}_{2}$ electrodes. Electrochem. Commun. 6, 1085-1091 (2004).

8. Armstrong, A. R. et al. Demonstrating oxygen loss and associated structural reorganization in the lithium battery cathode $\mathrm{Li}\left[\mathrm{Ni}_{0.2} \mathrm{Li}_{0.2} \mathrm{Mn}_{0.6}\right] \mathrm{O}_{2}$. J. Am. Chem. Soc. 128, 8694-8698 (2006).

9. Jiang, M., Key, B., Meng, Y. S. \& Grey, C. P. Electrochemical and structural study of the layered, 'Li-excess' lithium-ion battery electrode material $\mathrm{Li}\left[\mathrm{Li}_{1 /}\right.$ $\left.{ }_{9} \mathrm{Ni}_{1 / 3} \mathrm{Mn}_{5 / 9}\right] \mathrm{O}_{2}$. Chem. Mater. 21, 2733-2745 (2009).

10. Ohzuku, T., Nagayama, M., Tsuji, K. \& Ariyoshi, K. High-capacity lithium insertion materials of lithium nickel manganese oxides for advanced lithium-ion batteries: toward rechargeable capacity more than $300 \mathrm{~mA} \mathrm{~h} \mathrm{~g}^{-1}$. J. Mater. Chem. 21, 10179-10188 (2011).

11. Yabuuchi, N., Yoshii, K., Myung, S.-T., Nakai, I. \& Komaba, S. Detailed studies of a high-capacity electrode material for rechargeable batteries, $\mathrm{Li}_{2} \mathrm{MnO}_{3}-\mathrm{LiCo}_{1 / 3} \mathrm{Ni}_{1 / 3} \mathrm{Mn}_{1 / 3} \mathrm{O}_{2}$. J. Am. Chem. Soc. 133, 4404-4419 (2011).

12. Koga, H. et al. $\mathrm{Li}_{1.20} \mathrm{Mn}_{0.54} \mathrm{Co}_{0.13} \mathrm{Ni}_{0.13} \mathrm{O}_{2}$ with different particle sizes as attractive positive electrode materials for lithium-ion batteries: insights into their structure. J. Phys. Chem. B 116, 13497-13506 (2012).

13. Oishi, M. et al. Charge compensation mechanisms in $\mathrm{Li}_{1.16} \mathrm{Ni}_{0.15} \mathrm{Co}_{0.19} \mathrm{Mn}_{0.50} \mathrm{O}_{2}$ positive electrode material for $\mathrm{Li}$-ion batteries analyzed by a combination of hard and soft X-ray absorption near edge structure. J. Power Sources 222, 45-51 (2013).

14. Sathiya, M. et al. Reversible anionic redox chemistry in high-capacity layeredoxide electrodes. Nat. Mater. 12, 827-835 (2013).

15. Oishi, M. et al. Direct observation of reversible charge compensation by oxygen ion in Li-rich manganese layered oxide positive electrode material, $\mathrm{Li}_{1.16} \mathrm{Ni}_{0.15} \mathrm{Co}_{0.19} \mathrm{Mn}_{0.50} \mathrm{O}_{2}$. J. Power Sources 276, 89-94 (2015).

16. Saubanere, M., McCalla, E., Tarascon, J. M. \& Doublet, M. L. The intriguing question of anionic redox in high-energy density cathodes for Li-ion batteries. Energy Environ. Sci. 9, 984-991 (2016).

17. McCalla, E. et al. Visualization of O-O peroxo-like dimers in high-capacity layered oxides for Li-ion batteries. Science 350, 1516-1521 (2015).

18. Luo, K. et al. Charge-compensation in $3 d$-transition-metal-oxide intercalation cathodes through the generation of localized electron holes on oxygen. Nat. Chem. 8, 684-691 (2016).
19. Seo, D.-H. et al. The structural and chemical origin of the oxygen redox activity in layered and cation-disordered Li-excess cathode materials. Nat. Chem. 8, 692-697 (2016).

20. Yabuuchi, N. et al. High-capacity electrode materials for rechargeable lithium batteries: $\mathrm{Li}_{3} \mathrm{NbO}_{4}$-based system with cation-disordered rocksalt structure. Proc. Natl Acad. Sci. USA 112, 7650-7655 (2015).

21. Yabuuchi, N. et al. Synthesis and electrochemical properties of $\mathrm{Li}_{1.3} \mathrm{Nb}_{0.3} \mathrm{~V}_{0.4} \mathrm{O}_{2}$ as a positive electrode material for rechargeable lithium batteries. Chem. Commun. 52, 2051-2054 (2016).

22. Yabuuchi, N., Tahara, Y., Komaba, S., Kitada, S. \& Kajiya, Y. Synthesis and electrochemical properties of $\mathrm{Li}_{4} \mathrm{MoO}_{5}-\mathrm{NiO}$ binary system as positive electrode materials for rechargeable lithium batteries. Chem. Mater. 28, 416-419 (2016).

23. Wang, R. et al. A disordered rock-salt Li-excess cathode material with high capacity and substantial oxygen redox activity: $\mathrm{Li}_{1.25} \mathrm{Nb}_{0.25} \mathrm{Mn}_{0.5} \mathrm{O}_{2}$. Electrochem. Commun. 60, 70-73 (2015).

24. Lee, J. et al. A new class of high capacity cation-disordered oxides for rechargeable lithium batteries: Li-Ni-Ti-Mo oxides. Energy Environ. Sci. 8, 3255-3265 (2015).

25. McCalla, E. et al. Novel complex stacking of fully-ordered transition metal layers in $\mathrm{Li}_{4} \mathrm{FeSbO}_{6}$ materials. Chem. Mater. 27, 1699-1708 (2015).

26. Okuoka, S. et al. A new sealed lithium-peroxide battery with a Co-doped $\mathrm{Li}_{2} \mathrm{O}$ cathode in a superconcentrated lithium bis(fluorosulfonyl)amide electrolyte. Sci. Rep. 4, 5684 (2014).

27. Lee, J. et al. Unlocking the potential of cation-disordered oxides for rechargeable lithium batteries. Science 343, 519-522 (2014).

28. Chen, R. et al. $\mathrm{Li}^{+}$intercalation in isostructural $\mathrm{Li}_{2} \mathrm{VO}_{3}$ and $\mathrm{Li}_{2} \mathrm{VO}_{2} \mathrm{~F}$ with $\mathrm{O}^{2-}$ and mixed $\mathrm{O}^{2-} / \mathrm{F}^{-}$anions. PCCP 17, 17288-17295 (2015).

29. Ruckman, M. W. et al. Interpreting the near edges of $\mathrm{O}_{2}$ and $\mathrm{O}_{2}^{-}$in alkalimetal superoxides. Phys. Rev. Lett. 67, 2533-2536 (1991).

30. Hong, J. et al. Critical role of oxygen evolved from layered Li-excess metal oxides in lithium rechargeable batteries. Chem. Mater. 24, 2692-2697 (2012).

31. Yabuuchi, N., Kubota, K., Aoki, Y. \& Komaba, S. Understanding particle-sizedependent electrochemical properties of $\mathrm{Li}_{2} \mathrm{MnO}_{3}$-based positive electrode materials for rechargeable lithium batteries. J. Phys. Chem. C 120, 875-885 (2016).

32. McCalla, E. et al. Understanding the roles of anionic redox and oxygen release during electrochemical cycling of Lithium-rich layered $\mathrm{Li}_{4} \mathrm{FeSbO}_{6}$. J. Am. Chem. Soc. 137, 4804-4814 (2015).

33. Sathiya, M. et al. Origin of voltage decay in high-capacity layered oxide electrodes. Nat. Mater. 14, 230-238 (2015).

34. Urban, A., Lee, J. \& Ceder, G. The configurational space of rocksalt-type oxides for high-capacity lithium battery electrodes. Adv. Energy Mater. 4, 1400478 (2014).

35. Yu, D. Y. W., Yanagida, K., Kato, Y. \& Nakamura, H. Electrochemical activities in $\mathrm{Li}_{2} \mathrm{MnO}_{3}$. J. Electrochem. Soc. 156, A417-A424 (2009).

36. Ishii, H., Nakanishi, K., Watanabe, I., Ohta, T. \& Kojima, K. Improvement of ultra soft X-ray absorption spectroscopy and photoelectron spectroscopy beamline for studies on related materials and cathodes of lithium ion batteries. e-J. Surf. Sci. Nanotechnol. 9, 416-421 (2011).

37. Glazier, S. L., Li, J., Zhou, J., Bond, T. \& Dahn, J. R. Characterization of disordered $\mathrm{Li}_{(1+x)} \mathrm{Ti}_{2 x} \mathrm{Fe}_{(1-3 x)} \mathrm{O}_{2}$ as positive electrode materials in Li-Ion batteries using percolation theory. Chem. Mater. 27, 7751-7756 (2015).

38. Matsuhara, T. et al. Synthesis and electrode performance of $\mathrm{Li}_{4} \mathrm{MoO}_{5}-\mathrm{LiFeO}_{2}$ binary system as positive electrode materials for rechargeable lithium batteries. Electrochemistry 84, 797-801 (2016).

39. Newville, M. IFEFFIT: interactive XAFS analysis and FEFF fitting. Journal of Synchrotron Radiat. 8, 322-324 (2001).

40. Yonemura, M. et al. Development of SPICA, new dedicated neutron powder diffractometer for battery studies. J. Phys.: Conf. Ser. 502, 012053 (2014).

41. Izumi, F. \& Momma, K. Three-dimensional visualization in powder diffraction. Solid State Phenom. 130, 15-20 (2007).

42. Momma, K. \& Izumi, F. VESTA 3 for three-dimensional visualization of crystal, volumetric and morphology data. J. Appl. Crystallogr. 44, 1272-1276 (2011).

\section{Acknowledgements}

This research has been partly supported by Advanced Low Carbon Technology Research and Development Program of the Japan Science and Technology Agency (JST) Special Priority Research Area 'Next-Generation Rechargeable Battery'. The synchrotron X-ray diffraction experiments were made possible through the support of the Japanese Ministry of Education, Science, Sports and Culture, Nanotechnology Support Project (Proposals 2013B1752) with the approval of the Japan Synchrotron Radiation (SR) Research Institute. The hard X-ray absorption work was done under the approval of the Photon Factory Program Advisory Committee (Proposals 2014G055) and the soft X-ray absorption work was done at the SR Center of Ritsumeikan University under the 'Project for Creation of Research Platforms and Sharing of Advanced Research Infrastructure' (Proposal R1506 and R1549). M.N. is grateful for financial support from the JST Precursory Research for Embryonic Science and Technology program. We also thank the Information Technology Center of Nagoya University for providing computing resources (CX400). The neutron scattering experiment was approved by the Neutron Scattering 
Program Advisory Committee of IMSS, KEK (Proposal No. 2014S10). TEM observation was supported by Dr Keisuke Shinoda, NIMS, Battery Research Platform of the ALCA program. N.Y. thanks Dr Kimihiko Ito, NIMS, for the courtesy and permission to reproduce the data of $\mathrm{O} \mathrm{K}$-edge XAS spectra for $\mathrm{KO}_{2}$.

\section{Author contributions}

N.Y. and M.N. conceived and directed the project. M.T. and K.S. synthesized $\mathrm{Li}_{3} \mathrm{NbO}_{4-}$ based samples. Y.K. synthesized $\mathrm{Li}_{1.2} \mathrm{Ti}_{0.4} \mathrm{Mn}_{0.4} \mathrm{O}_{2}$. M.T., K.S. and Y.K. measured electrochemical properties of samples. Y.H., T.M. and H.S. conducted DFT calculations. A.N carried out XPS measurement. M.Y. measured and analysed neutron diffraction data. K.Y, K.M. and T.O. collected and analysed soft XAS spectra. N.Y., M.N., M.Y., S.K. and T.O. wrote the manuscript.

\section{Additional information}

Supplementary Information accompanies this paper at http://www.nature.com/ naturecommunications

Competing financial interests: The authors declare no competing financial interests.
Reprints and permission information is available online at http://npg.nature.com/ reprintsandpermissions/

How to cite this article: Yabuuchi $\mathrm{N}$, et al. Origin of stabilization and destabilization in solid-state redox reaction of oxide ions for lithium-ion batteries. Nat. Commun. 7, 13814 doi: 10.1038/ncomms13814 (2016).

Publisher's note: Springer Nature remains neutral with regard to jurisdictional claims in published maps and institutional affiliations.

\section{(c) (i)}

This work is licensed under a Creative Commons Attribution 4.0 International License. The images or other third party material in this article are included in the article's Creative Commons license, unless indicated otherwise in the credit line; if the material is not included under the Creative Commons license, users will need to obtain permission from the license holder to reproduce the material. To view a copy of this license, visit http://creativecommons.org/licenses/by/4.0/

(C) The Author(s) 2016 